九州大学学術情報リポジトリ

Kyushu University Institutional Repository

\title{
Study on the Japanese Aneurhynchus Westwood (Hymenoptera : Diapriidae)
}

Honda, Masako

Entomological Laboratory, Department of Agriculture, Kyushu University

https://doi.org/10.5109/22782

出版情報: 九州大学大学院農学研究院紀要. 14 (4)，pp.613-627，1968-11. Kyushu University バージョン：

権利関係 : 


\begin{abstract}
Journal of Faculty of Agriculture, Kyushu University, Vol. 14, No. 4
November 30, 1968
\end{abstract}

\title{
Study on the Japanese Aneurhynchus Westwood ${ }^{1}$ \\ (Hymenoptera : Diapriidae)
}

Masako HondA ${ }^{2}$

\section{Introduction}

The genus Aneurhynchus Westwood is a moderate genus of the subfamily Diapriinae and up to present it contains 20 Palaearctic, 4 Nearctic and 1 Ethiopian species. The genus is hitherto unknown from Japan, but the author examined more than five species which were collected at various localities in Japan. In this paper she describes three new species among them. The subfamily Diapriinae is now separated into three tribes. Aneurhynchis belongs to the tribe Psilinii in having the combination of the following characters : 14-segmented male antenna, its 2nd flagellar segment straight, wing without costalis and with marginalis separated from costal margin. In the tribe Psilinii, Aneurhynchus is closely related to A neuropria Kieffer, but it is easily separated from the latter by the large compound eye which is almost as long as gena, and the presence of basalis and stigmalis in the fore wing.

All the holotypes of these new species are preserved in the collection of the Entomological Laboratory, Kyushu University.

Before going further, the author expresses her thanks to Professor K. Yasumatsu and Professor Y. Hirashima of Kyushu University for their continuous guidance and suggestions in the course of the present work. Her deep thanks are also due to Professor C. Watanabe of Hokkaido University for his kindness in giving her the chance of examining the specimens of that Institute and to Professor T. Okutani of Kobe University for his kind help in taking many photocopies of literature preserved in the British Museum (Natural History). She is deeply grateful to Messrs. F. Nakasuji and K. Kusigemati for their kindness in putting many materials at her disposal,

1. Contribution Ser. 2, No. 284, Entomological Laboratory, Faculty of Agriculture, Kyushu University, Fukuoka.

2. Entomological Laboratory, Faculty of Agriculture, Kyushu University, Fukuoka. 
and Dr. K. Yano, Mr. T. Saigusa, Mr. A. Nakanishi, Mr. H. Shima and Mr. E. F. Drake for their useful advices and gifts of many materials. Her cordial thanks are due to Dr. L. Masner of Czechoslovak Academy of Science for giving her his reprints, for the loan of European specimens for comparison and for his kind guidance in many ways, and also to Dr. G. E. Nixon of the British Museum (Natural History) and Dr. W. Hellén of the University of Helsinki for their kind help rendered to her and for the gift of reprints.

\section{Morphological notes}

The nomenclatures of the body except wing adopted here are those defined in the Handbooks for the Identification of British Insects, Hymenoptera 6(1)

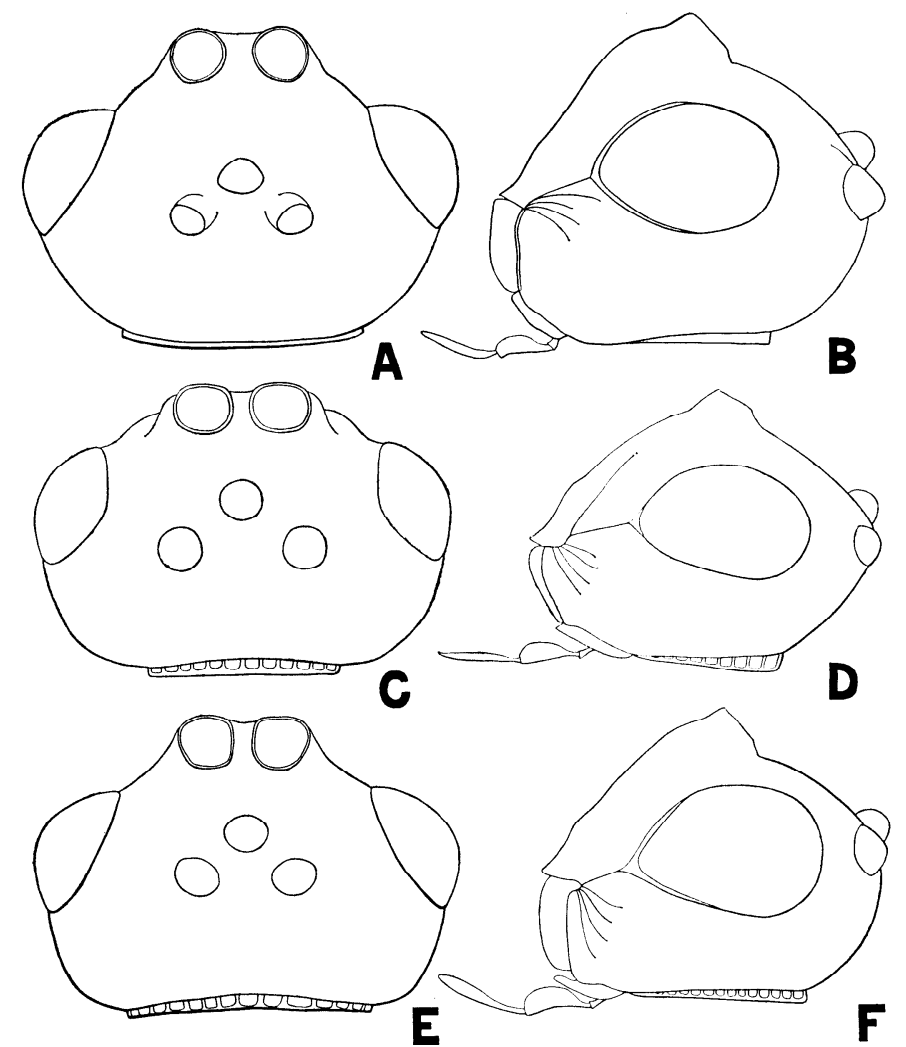

Fig. 1. A-F, Head in: A, Dorsal view of Aneurhynchus fuscibasalis sp. nov., o $^{\rightarrow}$. B, Lateral view, same. C, Dorsal view of A. fannivorus sp. nov., ठ․ D, Lateral view, same. E, Dorsal view of $A$. angulus sp. nov., ठ̋. F, Lateral view, same. 
and 8 (3). The nomenclatures of wing venation used here are derived from Kieffer's monograph on the Diapriidae (Das Tierreich 44).

Head : About 1.3 to 1.5 times as wide as long, 1.1 to 1.3 times as high as long. Clypeus weakly bulged under antenna1 socket with a lozenge-shaped projection ventrally, and with sparse or more or less dense hairs. Frons smooth. Vertex smooth and makes a dull or sometimes acute angle to frons. Compound eye large, subequal to gena in length, with very sparse short hairs. Ocelli arranged in a triangle, the ratio of the distance between hind ocelli and the distance between a hind ocellus and a compound

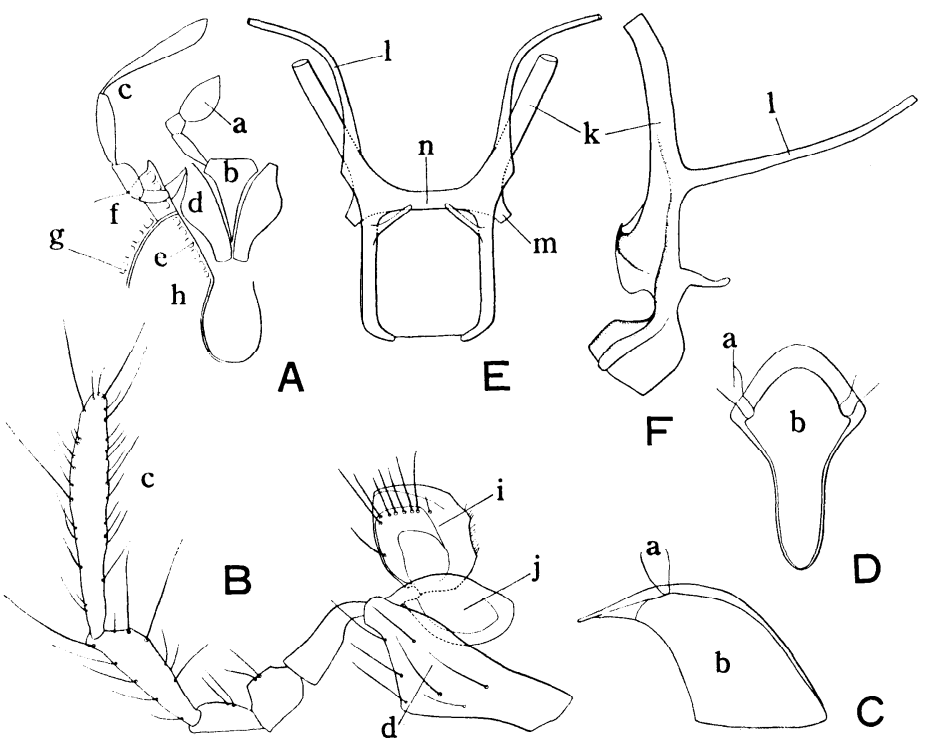

Fig. 2. Mouth-parts and Tentorium of Aneurhynchus angulus sp. nov., $\delta^{\Im}$. A, Mouth-parts in ventral view. B, Maxillary palp and stipes. C, Mentum in lateral view. D, Same, in antero-ventral view. E, Tentorium in dorsal view. F, Same, in lateral view. a, labail palp. b, mentum+glossa. c, maxillary palp. d, stipes + cardo. e, hypostomal carina. f, gena. g, occipital carina. h, post gena. i, galea. j, lacinia. $\mathrm{k}$, anterior tentorial pit. 1 , dorsal tentorial pit. $\mathrm{m}$, posterior tentorial pit. $\mathrm{n}$, tentorial bridge.

eye is more or less different in species. Gena with several wrinkles, one of them reaching to the anterior end of compound eye (subocular suture). The distance between outer edge of hypostomal carina and occipital carina is shorter than the width of post-gena, being about $2: 3$. There is a row of punctures along occipital carina usually, rarely without a row of this kind. Mouth-parts : Mandible very thickened basally with 2 teeth, and articulated at near of the upper end and the bottom of gena (the anterior 
end of hypostomal carina). Stipes and cardo combined into one large sclerite bearing a thin, pale galea and a lacinia, and 5-segmented maxillary palp, of which 1st to 3rd segments subequal in length, 4th segment slightly or fairly longer than 3rd and very broad, often becoming subtrapezoidal in form and 5th segment longer than 4 th, slender club-shaped, weakly pointed at tip. Labium consisting of prementum, submentum, glossa and paraglossa but united one dorsally curved lozenge-shaped sclerite bearing a pair of 3-segmented labial palpi, of which 1st segment short cylindrical or slender, 2nd segment short, about $1 / 2$ times as long as lst, subsquare in shape, 3rd segment broad and fusiform, about 3 times as long as 2nd. Hypostoma broad, well developed inwards. Hypostomal carina strongly arised (or gena strongly flanged) with a row of carina along its outer margin. Tentorium with anterior, dorsal and posterior pits on the inner surface of head. Anterior pits lie in malar space, above subocular suture about $1 / 3$ point from anterior margin of gena, dorsal pits lie in the middle of upper margin of compound eyes, posterior pits lie below or near ventral end of foramen, tentorial bridge thick. Tentorium rectangularly curved posteriorly and projecting from foramen. Antenna : Antenna inserted into antenna1 socket or projected frontal shelf. In male, 14-segmented. Scape long, thick, cylindrical with very sparse long or short hairs, and weakly curved inwards, pedicel small globular in shape with a few hairs, narrower than the thickness of scape. Flagellar segments oval, elongate oval or cylindrical in shape, with erect or suberect sensillae, subequal or shorter than the central thickness of flagellar segments and denser than those of scape and pedicel ; 1st flagellar segment always longer than pedicel, short cylindrical or elongate oval in shape, slender than the other segments ; 2nd flagellar segment (sex segment) thick and long with or without a subbasal angle laterally which sometimes becomes tooth-like ; 3rd to 4th or 6th segments as long as 2nd ; 5th to 11th segments gradually shortened to apex ; 12th segment fusiform, longer than 11th. In female, 12-segmented. Scape much longer than that of male, pedicel resembling male, but scape and pedicel with denser, short white hairs. Flagellar segment with also very short and white hairs much densely, becoming gradually thickened towards apex, but not distinctly clavate ; 1st flagellar segment long cylindrical ; 2nd flagellar segment also cylindrical and shorter than 1st ; 3 rd to 4 th or 5 th segments gradually shortened and thickened apically; apical 5 or 6 segments black, wider than the precedings, and usually wider than long ; 10th segment conical, longer than 9th.

Thorax : Pronotum visible dorsally, reaching to tegulae, with a row of punctures along or a little separated from posterior margin, and with a row of punctures along latero-ventral margin. Anterior neck-like part of pronotum provided with strong punctures or furrows. Lateral part of pronotum broad. Epomia well developed or absent. Propleuron contacts each 
other medianly, with a row of punctures laterally and sometimes medianly. Scutum is divided into median lobe and two lateral lobes by a pair of notaulices. Notaulices running through and only weakly converging or diverging posteriorly. Median lobe of scutum more or less convex, lateral lobes rather flattened or also convex. Scutum with or without a row of punctures along anterior margin. Scutellum usually with two foveae anteriorly. Ridge between them reaching or slightly distinct to scuto-scutellar suture. Postfoveal area broad, more or less convex with a few smaller hollows on each side, its lateral ridge straight or waved. Supra-alar spine well developed or absent. Subtriangular axilla strongly reticulated or hollowed. Posterior part of sutellum continued to axillary cord of the fore wing. Dorsal area of metascutellum usually steep with a median and lateral ridges which are continuing to the arising lateral cord of hind wing. Lateral area of metascutellum strongly carinulated or punctured. Mesepisternum extremely developed, mesepimeron reduced to a narrow transverse cord. A row of deep hollows (pleural suture) running through upwards from the outer articulation of mid coxa to wing process along mesepimeron. Subpleural area connected with the median sternal groove, and a broad precoxal furrow found between it and mesepisternum and the furrow is ended in a hollow anteriorly and gradually shallowed posteriorly. Propodeum with a median and lateral ridges (plica media and plica lateralis in C. G. Thomson's nomenclature) and a pair of stigmata strongly projected. Transverse submarginal carina usually observed in various form and often strongly flanged posteriorly, or rarely propodeum finely reticulated but without distinct carina. Lateral part of propodeum intimately fused with metapleuron, roughly and strongly reticulated. Ratio of the length of anterior half of propodeum (between anterior margin and transverse submarginal carina) to metascutellum in profile is useful to separate the species. Leg consists of a coxa, trochanter, femur, tibia and tarsus. Trochanter slender about $1 / 2$ times as long as femur. Femur stout, suddenly bulged in proximal part. Tibia with spurs 1, 2, 2, fore spur longer than the others; hind tibia slender, gradually thickened distally, longer than femur and as long as or slightly shorter than tarsus. Tarsus consists of 5 tarsomeres, 1st tarsomere of fore leg is strongly emarginated ventrally, and 5th tarsomere with arolium between two claws. Wing : 3 hooks arising from the front margin of hind wing. Fore wing with subcostalis, marginalis, stigmalis, basalis, discoidalis, radialis and analis. Subcostalis and marginalis separated from costal margin. Usually marginalis subtriangle in shape and continuing to stigmalis which ends in nod-like form. Subcostalis more or less bent at basalis. Subcostal space broad or narrow. Cubitalis strongly or relatively weakly curved posteriorly. Anal space not so broad. Hind wing with very weak veins, pale yellowish white. 
Abdomen : Petiole with a median and lateral ridges, the area between them with weaker 1 or 2 ridges in dorsal view, or finely reticulated or striated without any distinct ridges, sometimes bent ventrally. Gaster consists of 6 terga and 7 sterna ; 3rd tergum occupying most part of gaster, widest before or at the middle of gaster with 3 notches anteriorly and on each side of notches a few short and shallow furrows ; 4th to 6th terga of nothing but narrow rings, 7 th tergum with a pair of spiracles laterally ; 8th terga with a pair of shallow depressions ; 3rd sternum large, covering most part of gaster ventrally ; 4th to 8th sterna of narrow rings ; 9 th sternum subtriangle in shape.

Male genitalia : Genitalia bent ventrally at the base of paramere. Basalring with two small projections ventrally. Basiparamere with a pair of parameres which are distinctly bordered by sclerotized lines and provided with several sensory pores along distal margin. In its central menbranous area aedeagus is opened. Digitus situated on the ventral side of aedeagus, and provided with denticles and sensory pores along distal margin. Aedeagal apodeme attaching to aedeagus on the shoulders.

\section{Key to species}

1. Epomia present, transverse submarginal carina well developed . . . . . 2

- Epomia absent, so lateral part of pronotum gently connected to neck-like part ; flagellar segments of antenna slender cylindrical, 2nd flagellar segment about 1.6 times as long as lst, without a subbasal angle, 12th segment a little longer than 11th ; scutum and scutellum strongly convex, notaulice very narrow, propodeum finely reticulated throughout, without a transverse submarginal carina ; fore wing with broad, blackish brown basalis; gaster suddenly tapered in distal 6 segments ; in female, flagellar segments longer than wide, apical 5 segments forming a black club

fuscibasalis sp. nov.

2. Scape and pedicel blackish brown, or sometimes distal end of scape and pedicel reddish brown, flagellar segments oval, 2nd flagellar segment slightly longer than lst, 12th segment 1.5 times as long as 11 th ; notaulices very broad, in profile anterior half of propodeum about 1.3 or at most 1.5 times as long as metascutellum ; in female, 1st and 2nd flagellar segment cylindrical, 3rd segment oblique, slightly longer than wide fannivorus sp. nov.

- Scape and pedicel of antenna reddish brown, flagellar segments long, thick cylindrical with short erect sensillae, 2nd flagellar segment about 1.3 times as long as 1st with a subbasal angle which sometimes becomes tooth-like, 12th segment 1.3 to 1.4 times as long as 11 th ; epomia well developed, notaulices moderately broad, anterior half of propodeum about 2 times as long as metascutellum in profile ; in female, 1 st to 
3rd flagellar segments of antenna cylindrical, 4th segment oblique, slightly longer than wide angulus sp. nov.

\section{A neurhynchus fuscibasalis sp. nov.}

$\delta^{\top}$ : Head : Black. Mandible reddish brown, maxillary and labial palpi yellowish brown. Antenna blackish brown. Head 1.3 to 1.4 times as wide

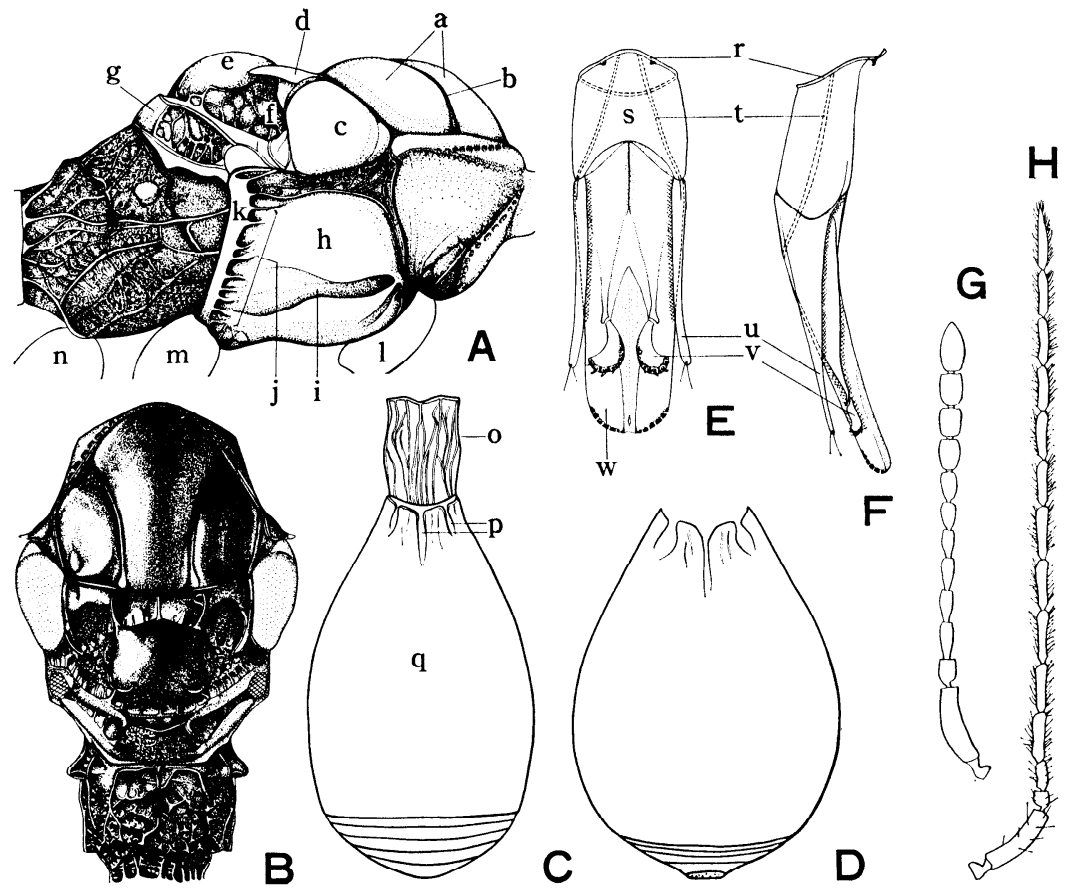

Fig. 3. Aneurhynchus fuscibasalis sp. nov... A, Thorax, in lateral view, ऊ. B, Same, in dorsal view. C, Abdomen, ơ. D, Gaster, 우. E, Male genitalia in ventral view. F, Same, in lateral view. G, Female antenna. H, Male antenna. a, mesoscutum. b, notaulices. c, tegula. d, supra-alar spine. e, scutellum. f, axilla. g, metascutellum. h, mesepisternum. $i$, precoxal suture. $j$, pleural suture. $\mathrm{k}$, mesepimeron. 1, fore coxa. m, middle coxa. $\mathrm{n}$, hind coxa. o, petiole. p, notch. q, 3rd tergum. r, basal ring. s, basiparamere. $\mathrm{t}$, aedeagal apodeme. u, paramere. v, digitus. w, aedeagus.

as long, 1.1 to 1.2 times as long as high. In profile frons making a right angle with clypeus and dull angle with vertex. Clypeus more or less bulged anteriorly. Occipital carina without punctures, only with a smooth 
suture. Compound eye small, fairly swollen, its minor axis shorter than gena. Ocelli fairly swollen, distance between hind ocelli 0.5 to 0.7 times as wide as distance between a hind ocellus and a compound eye. Antenna as long as body, hardly reaching to posterior end of body ; scape thick, cylindrical, 1.2 to 1.3 times as long as 2nd flagellar segment, pedicel globular ; flagellum cylindrical, with suberect sensillae as long as central thickness of flagellar segments ; 1st flagellar segment slender, short cylindrical, about 1.8 times as long as pedicel, 2nd flagellar segment cylindrical, without any subbasal tooth, 1.6 times as long as 1st flagellar segment, 3rd to 6th segments as long as or slightly longer than 2nd flagellar segment, 7th to 11th segments shorter than 2nd, 12th segment only slightly longer than 11th.

Thorax : Black and narrow. Pronotum with a row of very small and weak punctures on posterior submargin, with 2 or 3 weak and shallow furrows along antero-ventral margin, and central portion of pronotum weakly punctured. Mesoscutum strongly convex before or at the middle, without a row of punctures along anterior margin ; notaulices deep and very narrow without punctures along outer margin. Supra-alar spine well developed, scutellar foveae small, rather shallow, subsquare in shape, ridge between foveae reaching to scuto-scutellar border ; postfoveal area of scutellum strongly convex, slightly narrower than distance between outer margins of foveae, almost of the same width to posterior margin, its lateral ridge very weak or sometimes obsolete and even, with 1 small posterior fovea on each side; axilla continued to scutellum or only weakly separated by its lateral ridge. Metascutellum reticulated, with a weak median rather indistinctly lateral ridges, or without both median and lateral ridges, in profile metascutellum not steep, so dorsal margin of metascutellum to

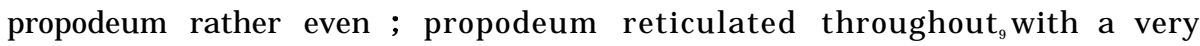
weak median ridge and without lateral ridges, transverse submarginal carina absent or very indistinct. Lateral portion of propodeum and metapleuron finely reticulated. Legs reddish brown, 5th tarsomere blackish brown, coxa of hind leg much darker. Proportion :

\begin{tabular}{|c|c|c|c|c|c|c|c|c|c|c|c|c|}
\hline \multirow{2}{*}{\multicolumn{2}{|c|}{ Femur }} & Tibia & Tarsus & \multicolumn{5}{|c|}{ Tarsomere } & \multicolumn{4}{|c|}{ Tibia : 1st t. 1st t. : 2nd } \\
\hline & & & & 1 st & 2nd & $3 r d$ & 4 th & 5 th & & & & \\
\hline Fore leg & 1.2 & 1 & 1.5 & 3.8 & 1.5 & 1.2 & 1 & 2.1 & 1.6 & 1 & 3.1 & 1 \\
\hline Middle & 1 & 1.3 & 1.3 & 3.7 & 1.6 & 1.3 & 1 & 2.2 & 2.3 & 1 & 2.4 & 1 \\
\hline Hind & 1 & 1.4 & 1.4 & 3.9 & 1.6 & 1.3 & 1 & 1.8 & 2.4 & 1 & 2.4 & 1 \\
\hline
\end{tabular}

t. = tarsomere

Wing : 2.3 to 2.5 times as long as wide. Veins strongly darkened, subcostalis, marginalis and stigmalis blackish brown, radialis, cubitalis, discoidalis and medialis more or less pale blackish brown, basalis and analis blackish brown, broad. Subcostal space narrow. Subcostalis strongly bent at basalis. Cubitalis strongly curved posteriorly.

Abdomen : Petiole moderately long, about 1.6 times as long as wide, 
curved ventrally or sometimes straight, shallowly striated throughout. Anterior margin of 3rd abdominal tergum just as wide as petiole, strongly incised, with a few weak furrows or only hollows on each side of notches. Gaster widest at or behind the middle, 1.7 to 1.9 times as long as wide, 2.2 to 2.5 times as long as thick. Genitalia : Digitus with 4 denticles on pos$\mathrm{t}$ erior margin.

우: Resembling male but different as follows. Antenna 12-segmented. First to 5th flagellar segments of antenna concolorous with scape and pedicel, reddish brown ; antenna about 0.7 times as long as body, reaching to posterior end of petiole, with a 5-segmented black club ; scape thick, cylindrical as long as following 3 segments taken together, pedicel slightly longer than wide, all flagellar segments longer than wide, 1st flagellar segment 1.5 times as long as pedicel, 1st to 5th flagellar segments cylindrical, becoming gradually shorter, 6th to 10th segments forming a 5-segmented club, and each segment longer than wide, 10th segment about 1.6 times as long and same wide as 9th. Petiole 1.4 times as long as wide. Gaster very broad posteriorly, suddenly narrowed in apical 6 segments, 1.4 times as long as wide, 1.9 to 2 times as long as thick.

Remarks : This new species is very distinct from the other known species of the genus by the following characters. Fore wing with dark and broad basalis. Scutellum strongly convex. Propodeum finely reticulated without a transverse submarginal carina.

Length : 3-3.5 mm.

Distribution : Hokkaido, Japan.

Holotype ðぇ: Yubari-dake, Sorachi Prov., Hokkaido, 16. VII. 1967, M. Honda leg.

Paratypes : 1 우 Wakkasakanai, Sôya Prov., 1. VII. 1967, T. Saigusa leg. ; $1 \precsim$ Rausu-dake, Shari, Abashiri Prov., 22. VI. 1967, T. Saigusa leg. ;4 ð Yubari-dake, Sorachi Prov., 15. VII. 1967, T. Saigusa leg.; 1 ๙ same locality and collector, 16. VII. 1967 ; 1 우 same locality and date, A. Nakanishi leg. ;2ðð Berabonai, Ashoro, Tokachi Prov., 22. VII. 1967, M. Honda leg. ; 1 ` same locality and date, H. Shima leg.

\section{A neurhynchus fannivorus sp.nov.}

๙ : Head : Black. Mandible reddish brown to blackish brown, with a black apical portion ; maxillary palpus yellow, labial palpus yellowish brown to reddish brown. Antenna blackish brown ; pedicel sometimes reddish brown, flagellum more or less paler towards tip. Head 1.3 to 1.5 times as wide as long, 1.2 to 1.3 times as high as long. In profile frons making a right or acute angle with vertex. Compound eye fairly swollen. Ocelli 
projected, hind ocelli widely separated, distance between theml.O to 1.1 times as wide as distance between a hind ocellus and a compound eye. Antenna 0.8 to 0.9 times as long as body, reaching to the middle of abdomen ; scape slightly shorter than 3 following segments taken together, pedicel globular ; flagellum oval, with suberect or erect sensillae which are $1 / 2$ to $2 / 3$ times as long as central thickness of flagellar segment, but those on 2 nd and 12 th segments sometimes shorter than $1 / 2$ of thickness ; 1 st flagellar segment about $2 / 3$ times as thick as 2nd, 2nd flagellar segment thick, slightly longer than lst, 3rd to 6th segments elongate oval and almost as long as 2nd, 7th to 11th segments oval to weakly elongate oval, 4/5 times as long as 2nd, 12th segment fusiform, 1.5 times as long as 11th.

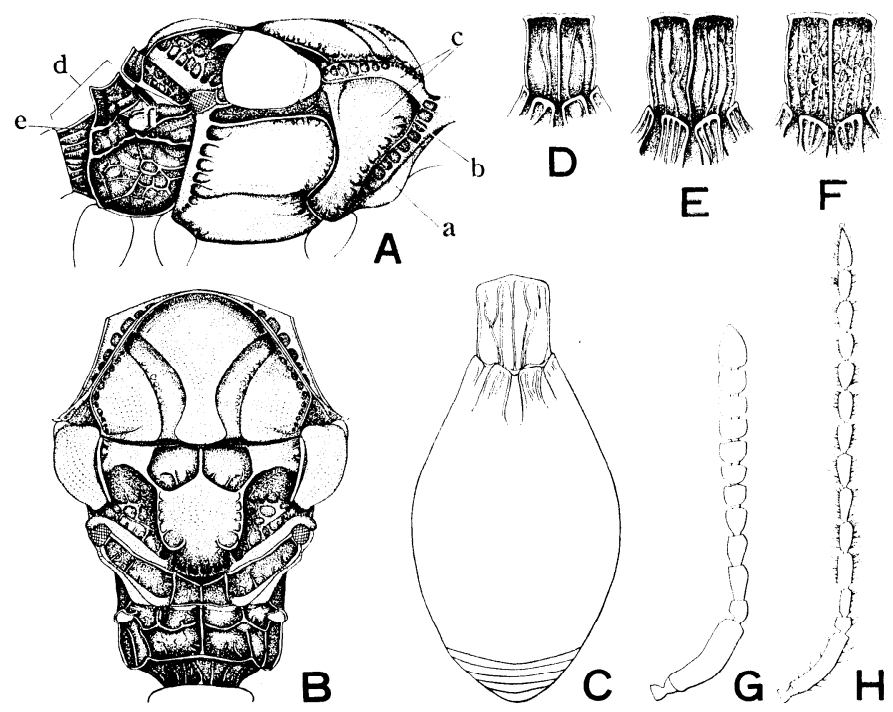

Fig. 4. Aneurhynchus fannivorus sp. nov. A, Thorax in lateral

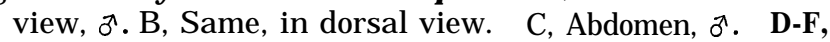
Petiole, variation of sculpture, $\varpi^{\top} . \mathrm{G}$, Female antenna. $\mathrm{H}$, Male antenna. a, propleuron. b, epomia. c, pronotum. d, propodeum. e, transverse submarginal carina. f, spiracle.

Thorax : Black and broad. Pronotum with a row of punctures along posterior margin. Mesoscutum moderately convex before the middle of median scutal area, slightly convex or rather flattened on lateral scutal area ; notaulices very broad, often much widened on posterior half, and with weak punctures along outer margin. Supra-alar spine of scutellum (a hook-like projection on each side of scutellum) well developed, scutellar foveae deep and subpentagonal in shape, ridge between foveae reaching to scuto-scutellar suture ; postfoveal area of scutellum slightly nar- 
rower than distance between outer margins of foveae, and only slightly convex, its lateral ridge sharply defined and even, sublateral hollow divided into 2 or 3 small anterior hollows and a large posterior hollow ; axillary punctures distinctly separated from postfoveal area by its lateral ridges. Metascutellum with 3 distinct longitudinal ridges, in profile metascutellum steep. Propodeum weakly, roughly and irregularly rugose, with a distinct medin longitudinal ridge, and 2 or 3 lateral ridges, transverse submarginal carina almost straight or weakly incised anteriorly, and strongly angled at sides in posterior view. Anterior half of propodeum about 1.3 or at most 1.5 times as long as metascutellum in profile. Lateral portion of propodeum and metapleuron roughly reticulated. Legs reddish brown, coxa and 5th tarsomere blackish brown. Spurs 1, 2, 2, fore spur long, 0.6 to 0.8 times as long as 1st tarsomere. Proportion :

\section{Femur Tibia Tarsus Tarsomere} 1st 2nd 3rd 4th 5th

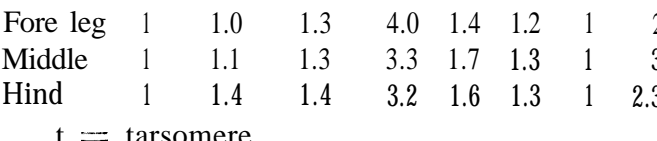

Tibia :'lst t. 1st t. : 2nd t.

$\begin{array}{cccc}1.7 & 1 & 2.8 & 1 \\ 2.8 & 1 & 1.9 & 1 \\ 3.1 & 1 & 2 & 1\end{array}$

Wing : 2.4 to 2.6 times longer than wide, veins pale, basalis, medialis, analis and discoidalis yellowish white and very indistinct, radialis and cubitalis more or less distinct, yellowish brown, subcostalis moderately bent at basalis, portion beyond basalis rather straight or slightly bowed.

Abdomen : Petiole slightly longer than wide, 1.2 to 1.3 times as long as wide, very weakly curved ventrally, with a distinct median ridge and lateral ridges, and 1 or 2 irregular and weaker ridges between them, otherwise weakly and roughly rugose. Anterior margin of 3rd abdominal tergum weakly incised anteriorly. Gaster thick, gradually tapering posteriorly, narrower than thorax, widest before or at the middle, 1.6 to 1.7 times as long as wide.

우: Resembling male but different as follows. Antenna 12 segments, about $1 / 2$ times as long as body, reaching to the posterior end of metascutellum, flagellum gradually thickened towards tip, not distinctly clavate ; scape slightly longer than 3 following segments taken together, 1st flagellar segment long cylindrical, 1.3 times longer and slightly slender than 2nd, 1st and 2nd segments distinctly longer than wide, 3rd segment oblique, hardly longer than wide, 4 th to 9 th segments more or less oblique, wider than long, 10th segment conical, almost 2 times as long as 9 th.

Abdomen : Petiole as long as wide, or slightly wider than long. Gaster broad, wider than thorax.

Host : Many specimens were reared from puparia of Fannia sp., close to $\boldsymbol{F}$. difficilis Stein in 1963. To complete one life cycle from egg to adult 24 
to 33 days are necessary.

Remarks : This species may be distinguished from the other known species of the genus by the entire blackish brown antenna and the oval flagellar segments, and very broad notaulices.

Length : 3-3.5 mm.

Distribution : Hokkaido and Kyushu, Japan.

Holotype ð: Fukuoka, Fukuoka Pref., Kyushu, 7.VI.1954, K. Morimoto leg.

Paratypes : $1 \precsim$ Sapporo-city, Hokkaido, 12. VII. 1967, A. Nakanishi leg. ; 1 우 Sapporo-city, 9. VI. 1965, K. Kusigemati leg. ;1 $\delta^{\top}$ Fukuoka, Fukuoka Pref., Kyushu, 7.VI.1954, K. Morimoto leg. ,38ðð 11 우우 Fukuoka, Fukuoka Pref., F. Nakasuji leg. (reared from puparia of Fannia sp.) 1963, date as follows ;

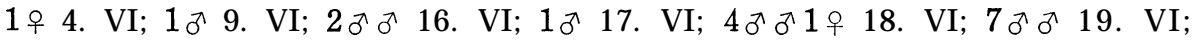

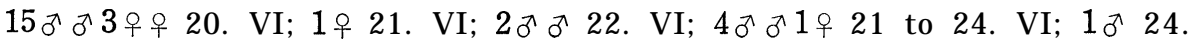
VI ; 1 우 25. VI ; 2 ð 1 우 ?. VI ; 1 ð 2. VII ; 1 우 Hakozaki, Fukuoka, Fukuoka Pref., 31. VI. 1964, Y. Miyatake leg. ;1우 same locality, 27. VI. 1966, E. F. Drake leg. ; 1우 Hirao, Fukuoka Pref., 12. IV. 1965 ;1우Inunaki-yama, Fukuoka Pref., 5. V. 1966, A. Nakanishi leg.

\section{Aneurhynchus angulus sp. nov.}

§ : Head : Black. Mandible reddish brown with its apical portion black, maxillary and labial palpi yellow, antenna1 scape and pedicel reddish brown to brown, flagellar segments blackish brown to black with basal part of each segment reddish brown. Head 1.3 to 1.4 times as wide as long, 1.1 to 1.3 times as high as long. In profile frons making a dull angle with vertex. Compound eye fairly swollen, ocelli not strongly projected, distance between hind ocelli 0.6 to 0.8 times as wide as distance between a hind ocellus and a compound eye. Antenna 0.9 to 1.1 times as long as body, reaching to near the posterior end of abdomen ; scape thick and cylindrical, 2 times as long as 1st segment, pedicel globular, almost as long as wide; flagellar segment cylindrical with erect or more or less suberect sensillae $1 / 2$ to $2 / 3$ times as long as central thickness of flagellar segment, 1st flagellar segment slender, cylindrical, at least 2 times as long as pedicel, 2nd to 11th segments thick and long cylindrical, gradually becoming a little slender towards apex, 2nd flagellar segment about 1.3 times as long as lst, with a subbasal angle which often becomes strongly tooth-like, but sometimes only weakly angled, 3rd to 5th flagellar segments as long as 2 nd, 6 th to 11 th segments almost equal in length to each other, 12th segment 1.3 to 1.4 times as long as penultimate segment, pointed at tip.

Thorax : Black and broad. Pronotum with a row of strong foveae along posterior margin, without punctures along antero-ventral margin. Mesoscutum slightly convex before the middle of median scutal area, rather flattened on lateral scutal area, notaulices broad and smooth, often with 
very weak punctures along its outer margin. Supra-alar spine well developed, scutellar foveae large and deep, subpentagonal in shape, ridge between foveae almost reaching to scuto-scutellar suture, postfoveal area of scutellum broad, subequal to or wider than distance between outer margins of foveae at the middle, its lateral ridge obscured or rarely defined and uneven, with 1 or 3 small anterior and 1 or 2 large posterior hollows ; axillary punctures not separated distinctly from postfoveal area. Metascutellum with a strong median ridge and weaker lateral ridges, or roughly and irregularly rugose and reticulated, in profile metascutellum steep, so dorsal margin from metascutellum to propodeum uneven ; propodeum with 3 dis-

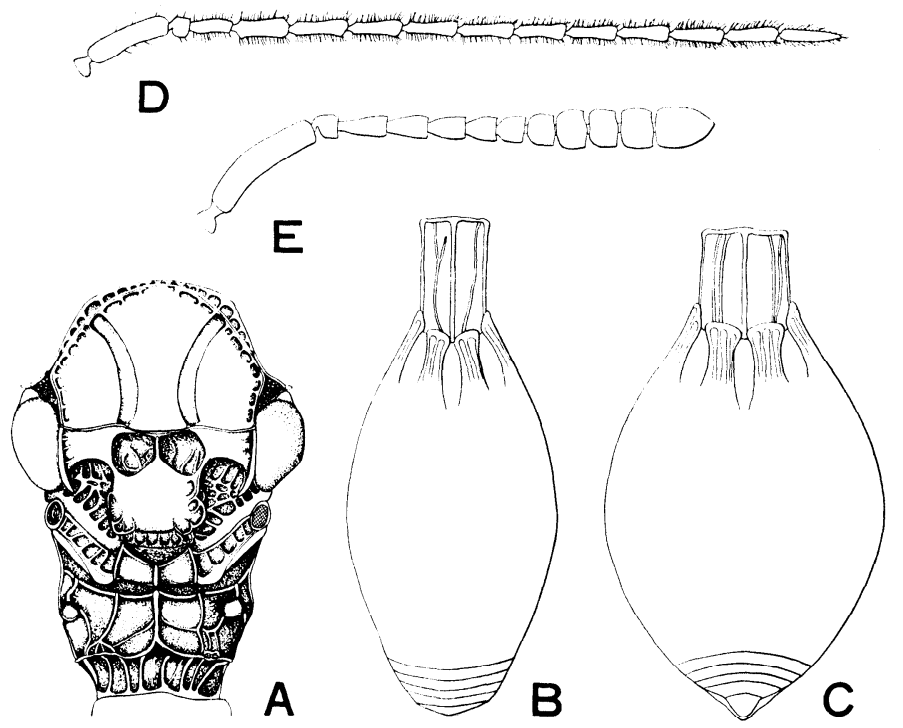

Fig. 5. Aneurhynchus angulus sp. nov. : A, Thorax in dorsal view, ō. B, Abdomen, ð. C, Same, ㅇ․ D, Male antenna, E, Female antenna.

tinct longitudinal ridges, transverse submarginal carina strong, incised and weakly bidentate laterally. Anterior half of propodeum about 2 times as long as metascutellum in profile. Lateral portion of propodeum and metapleuron roughly and strongly reticulated. Legs reddish brown, gradually paled apically, 5th tarsomere darker. Spurs 1, 2, 2. Proportion :

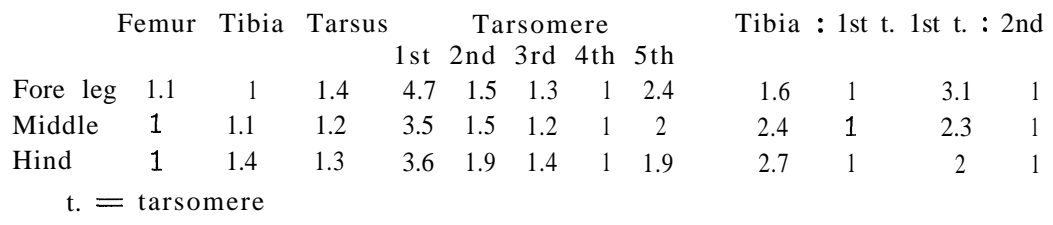

Wing :2.4 to 2.5 times longer than wide. Veins brown, subcostalis, mar- 
ginalis and stigmalis dark brown, radialis, cubitalis, discoidalis and medialis paler brown, basalis yellowish brown. Subcostal space narrow, subcostalis straight or only weakly bowed beyond basalis, cubitalis strongly curved posteriorly.

Abdomen : Petiole moderately long, about $\mathbf{1 . 4}$ times as long as wide, with a strong median ridge and lateral ridges, and 1 or 2 strong or weaker ridges between them, otherwise striated. Anterior margin of 3rd abdominal tergum incised somewhat triangularly as shown in textfigure. Gaster wider before or at the middle, 1.7 to 1.9 times as long as wide, flattened, gradually tapering towards tip. Genitalia :Digitus with 3 denticles along distal margin.

우: Resembling male but different as follows. Antenna 0.6 to 0.7 times as long as body ; 1 st to 4 th or 5 th flagellar segments concolorous with scape and pedicel, reddish brown, 5th or 6th to 10th segments black, flagellum gradually thickened towards tip, not distinctly clavate ; scape thick, long cylindrical and slightly longer than 3 following segments taken together, pedicel slightly longer than wide, 1st to 3rd flagellar segments distinctly longer than wide, 4th segment oblique, slighly longer than wide, 5 th to 10th segments wider than long, 7 th to 9 th segments about the same length and same width, 10th segment 2 times as long as 9th. Petiole almost as long as wide, or slightly longer. Gaster wider than thorax, about 1.5 to 1.6 times as long as wide.

Remarks : This species may be distinguished by long cylindrical antenna1 segments with a subbasal tooth-like projection on sex segment, short erect sensillae of flagellar segments.

Length : 3.5-5 mm.

Distribution : Hokkaido, Japan.

Holotype $0^{7}$ : Kiyokawa, Ashoro, Tokachi Prov., Hokkaido, 23. VII. 1967, T. Saigusa leg.

Paratypes : 1 우 Sapporo, Ishikari Prov., Hokkaido, 16. VII. 1958, S. Ueda leg. ; 1 우 same locality, 20. VII. 1965, K. Kusigemati leg. ;33 ðð 1 우 Ashoro, Tokachi Prov., 1967, date and collecters as follows ;1우 Kamiwashipp, 19. VI. T. Saigusa leg. ; $12 \succsim^{\top}$ Berabonai, 22. VII. A. Nakanishi leg. ; same date and locality, 1ठ T. Saigusa leg. ; 1 우 M. Honda leg. ; 5 ð § Berabonai, 24. VII. A. Nakanishi leg. ; same date and locality, $1 \sigma^{\Uparrow} \mathrm{H}$. Shima leg. ; $3 \delta^{-\top} \delta^{\top}$ M. Honda leg. ; 4 ठ Kiyokawa, 23. VII. A. Nakanishi leg. ; same date and locality, 28 ๙ H. Shima leg. ; 1 ð M. Honda leg. ; $3 \precsim$ T. Saigusa leg.

\section{References}

Cockerell, T. C. A. 1916. British Fossil Insects. Proc. U. S. Nat. Mus. 49 : 482-483. Hellén, W. 1963. Die Diapriinen Finland (Hymenoptera: Proctotrupoidea). Fauna Fennica 
$14: 3-35$.

Kieffer, J. J. 1911. In André, Species des Hyménoptères d'Europe et d'Algérie 10 : 815 831.

Kieffer, J. J. 1916. Diapriidae. Das Tierreich 44 : 329-338.

Masner, L. et A. Sundholm 1959. Some nomenclatoric problem in Diapriidae (Hym., Proctotrupoidea). Acta Soc. Ent. Cechosl. 56 : 161-168.

Muesebeck, C. F. W., Krombein, V. K., Towns, H. K. and others 1951. Hymenoptera of America North of Mexico. Synopitc Catalog. U. S. Dep. Agr., Agr. Monogr. No. 2 : 674-675.

Muesebeck, C. F. W. in Krombein 1958. Hymenoptera of America North of Mexico. Synoptic Catalog (Agriculture Monograph No. 2). First Supplement: 90.

Muesebeck, C. F. W. et L. Masner in Krombein 1967. Hymenoptera of America North of Mexico. Synoptic Catalog (Agriculture Monograph No. 2). Second Supplement : 289.

Nixon, G. E. J. 1957. Diapriidae subfamily Belytinae. Handbooks for the Identification of British Insects. Roy. Ent. Soc. London VIII (3).

Richards, 0. W. 1956. Hymenoptera introduction and key to families. Handbooks for the Identification of British Insects. Roy. Ent. Soc. London VI (1).

Thomson, C. G. 1858. Öfversigt af Kongl. Vetenskaps-Akademiens Förhandlingar 15: 376377.

Uemoto, K. 1961. Studies on the ecology of the Hymenopterous parasites of flies in Japan. J. Kyoto Pref. Univ. Med. 70(5): 1663-1712. 